\title{
Single Phase Line Frequency Commutated Voltage Source Inverter Suitable for
}

\section{Fuel Cell Interfacing}

\author{
G. Spiazzi*, S. Buso*, G.M. Martins ${ }^{* *}$, J.A. Pomilio** \\ *Department of Electronics and Informatics - University of Padova \\ Via Gradenigo 6/a, 35131 Padova - ITALY \\ Phone: +39-049-827.7525 Fax: +39-049-827.7599/7699 \\ e-mail: giorgio.spiazzi@dei.unipd.it \\ ${ }^{* *}$ School of Electrical and Computer Engineering - State University of Campinas \\ C. P. 6101 13081-970 Campinas - Brazil \\ Phone: +55-19-788.3748 Fax: +55-19-3289.1395 \\ e-mail:antenor@dsce.fee.unicamp.br
}

\begin{abstract}
The paper describes a single-phase dc-ac topology for interfacing de sources with the utility grid. In particular, the application to fuel cells is considered. The converter operates without batteries or any other energy storage device, so island mode operation is not possible. The commutation of the power switches is at the line frequency. This gives the converter several interesting properties such as: negligible switching losses, negligible EMI generation and higher reliability compared to PWM inverters (due to the much simpler control circuitry). Moreover, thanks to a suitable modulation strategy, the current injected into the grid presents almost unity displacement factor in a wide power range.
\end{abstract}

\section{INTRODUCTION}

Generation systems based on renewable energy sources typically need an electronic interface to condition the locally generated power and to provide a connection to the utility grid. The electronic power converter implementing the interface has to supply the local loads and inject the exceeding power into the grid. Both tasks can be performed by a PWM controlled voltage source inverter (VSI), directly supplied by the renewable energy source [1], which is often a dc source. This solution provides high quality output voltage and current waveforms, allowing an efficient power transfer to the grid, with practically unity power factor. On the other hand, PWM VSIs are characterized by relatively low efficiency, because of switching losses, and considerable EMI generation. Moreover, in the particular case of low-power, co-generation applications [2], based on photo-voltaic panels or fuel cells, they often appear to be excessively expensive. The same cost limitation applies to the other topologically different solutions, suitable for grid interface application, as those discussed in [3]. Using high frequency commutation, they call for EMI filters to attenuate the high frequency harmonic content of the current waveform.

This paper analyses a single phase, line frequency commutated voltage source inverter (VSI) usable as a rugged and low-cost interface between a renewable dc source and the utility grid. The target application is represented by low to medium power fuel cells used in cogeneration systems. The interface does not include batteries and, accordingly, is designed to efficiently operate only at constant output power. In other words, operation in the absence of grid voltage is not allowed. In addition, the use of a series connection of commercial fuel cell systems may be required to reach the input dc voltage needed to correctly operate the converter. Switching at the line frequency, the converter presents negligible switching losses and EMI generation. Besides, the simplicity of the required control circuitry makes it particularly robust and inexpensive.

The converter has been originally presented in [4], where low frequency EMC aspects have been discussed in detail. The focus of this paper is instead on the analysis, modeling and control of the converter for the considered specific application. The paper includes the detailed analysis of the converter in CCM and DCM. The analysis allows to outline

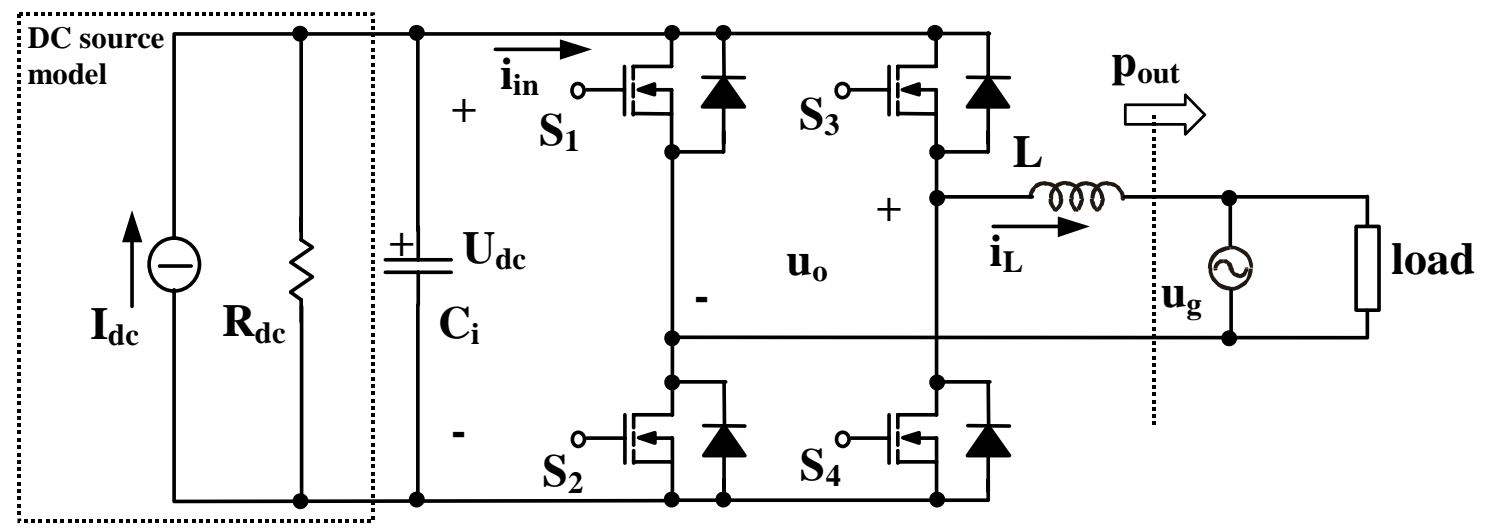

Fig. 1 - Converter basic scheme. 


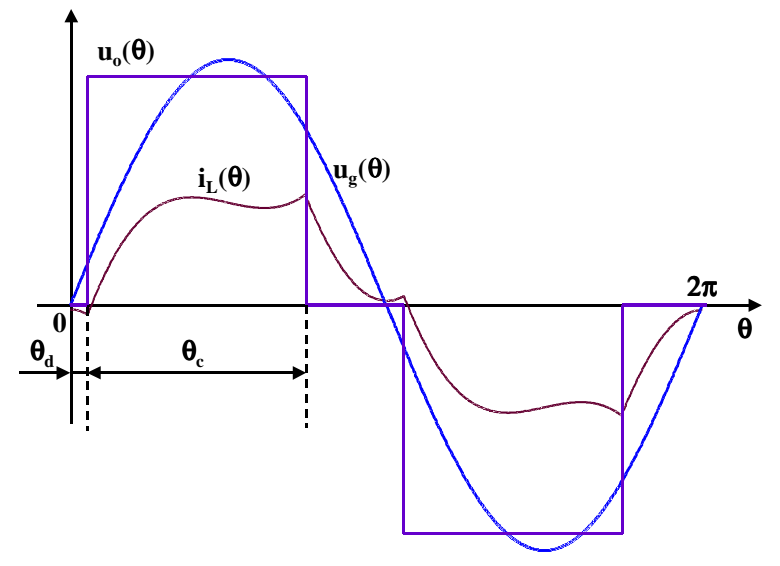

Fig. 2 - Inverter output voltage and current waveforms together with line voltage waveform in a line period (CCM).

a design procedure both for the converter passive components and for the basic control parameters, defining an optimal modulation strategy. Based on this, it is possible to control the power flux to the utility grid in a wide range, while maintaining the current displacement factor close to unity.

A small signal dynamic model is also derived, suitable for control stability analysis. Experimental results are given, that validate the theoretical analysis and demonstrate the feasibility of the approach.

\section{CONVERTER DESCRIPTION AND BASIC OPERATION}

The proposed single-phase inverter is shown in Fig. 1. The converter supplies the load with power coming from a dc source (fuel cell), which we represent with its Norton equivalent. This allows us to account for the non negligible output impedance of the cell i.e. to model its typical voltage/current characteristic [5-7], at least in the so-called ohmic polarization region. Parameter values can be directly derived from the typical proton exchange membrane fuel cell (PEMFC) characteristic (cell voltage / current density). Considering, for example, a nominal output voltage of $200 \mathrm{~V}$ (at nominal output current) and a nominal power of $2.5 \mathrm{~kW}$ we determined $\mathrm{I}_{\mathrm{dc}}=24 \mathrm{~A}, \mathrm{R}_{\mathrm{dc}}=16.7 \Omega$. The converter is actually fed by a dc voltage $U_{d c}$, across capacitor $\mathrm{C}_{\mathrm{i}}$, which, given the non ideal characteristics of the source, has to be suitably regulated. The dc source operating point is controlled by adjusting the average input current $\mathrm{I}_{\text {in }}$ absorbed by the power converter so as to keep the dc link voltage $U_{d c}$ at the desired level. In general, for a correct converter operation, an input voltage close to the line peak voltage may be required. As a consequence, the fuel cell stack needs to be specifically designed or the series connection of several commercial stacks may be considered. The basic converter operation is as a controlled current source. By forcing the fundamental component of current $i_{L}$ to be in phase with voltage $u_{g}=U_{g} \cdot \sin (\theta), \theta=\omega t$, one can minimize the current required to extract the nominal active power from the $\mathrm{dc}$ source. The regulation of the active power injected into the grid allows to vary the average input current $\mathrm{I}_{\text {in }}$ and so to control the input voltage and the cell operating point. Since the grid determines the load voltage, possible exceeding power coming from the dc source is

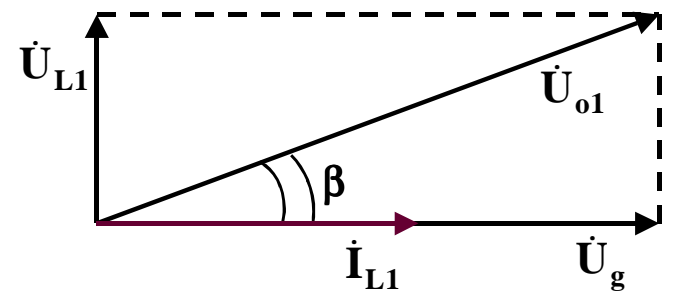

Fig. 3 - Vector diagram of fundamental inductor voltage $\dot{U}_{\mathrm{L} 1}$, line voltage $\dot{U}_{\mathrm{g}}$, inverter output voltage fundamental component $\dot{\mathrm{U}}_{\mathrm{o} 1}$ and inductor fundamental current $\dot{\mathrm{I}}_{\mathrm{L} 1}$, assuming only active power delivered to the line.

automatically injected into the utility. Similarly, reactive power required by the load circulates through the grid and does not affect the converter. As can be seen, no battery or other significant energy tank is connected to the dc/ac converter. Because of that, it is not possible to accept significant variations of the regulated output power. These would cause inefficient use of fuel and/or significant power dissipation within the cell. As known, any fuel cell response to modifications in the fuel flow presents typical time constants between one to a few minutes. Consequently, operation in the absence of the grid is not possible, unless an energy storage device is included in the system. In case of a grid fault, our system has to be disconnected.

\section{CONVERTER ANALYSIS IN CCM}

Assuming the converter operates in CCM, as with any three level modulation strategy (e.g. phase shift modulation), the converter main waveforms are shown in Fig. 2. As can be seen, the inverter generates a three-level voltage pulse with adjustable conduction angle $\theta_{c}$ and delay angle $\theta_{\mathrm{d}}$ with respect to the line voltage $\mathrm{u}_{\mathrm{g}}$ zero crossing.

According to our control strategy, we want the converter output current $\mathrm{i}_{\mathrm{L}}$ to be in phase with the line voltage $\mathrm{u}_{\mathrm{g}}$. We also want to maintain the input voltage $\mathrm{U}_{\mathrm{dc}}$ at a given value, which requires the control of the average input current $\mathrm{I}_{\text {in }}$. Deriving the expression of the inverter voltage fundamental harmonic component, as a function of control and converter parameters, it is possible to find the conditions on angles $\theta_{c}$ and $\theta_{\mathrm{d}}$ which need to be satisfied in order to get the desired result. The situation is described by the vector diagram, referring to the fundamental components, shown in Fig. 3.

Imposing the phase condition ( $\mathrm{i}_{\mathrm{L}}$ in phase with $\mathrm{u}_{\mathrm{g}}$ ), we derived the constraint (1), which relates angles $\theta_{\mathrm{c}}$ and $\theta_{\mathrm{d}}$.

$$
\cos \left(\theta_{\mathrm{d}}\right)-\cos \left(\theta_{\mathrm{d}}+\theta_{\mathrm{c}}\right)=\frac{\pi}{2 \mathrm{M}}
$$

where $\mathrm{M}=\frac{\mathrm{U}_{\mathrm{dc}}}{\mathrm{U}_{\mathrm{g}}}$.

Then, by imposing the output power to be equal to a given amount $\mathrm{P}_{\mathrm{g}}$, we derived constraint (2).

$$
\sin \left(\theta_{d}+\theta_{c}\right)-\sin \left(\theta_{d}\right)=P_{g N},
$$

where $P_{g N}=\frac{P_{g}}{P_{N}}=P_{g} \frac{\pi \omega_{g} L}{U_{d c} U_{g}}$ is the normalized output power delivered to the line. 


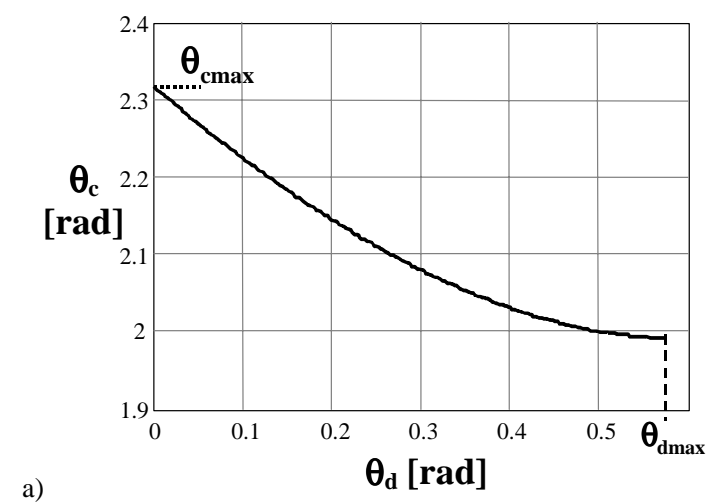

a)

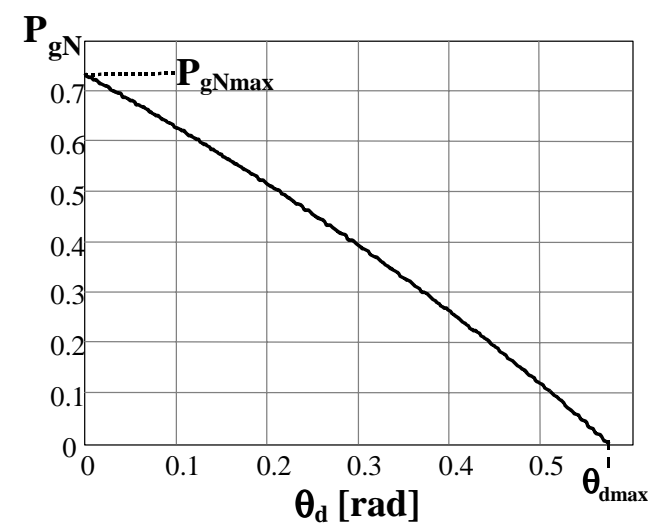

b)

Fig. 4 - a) relation between conduction angle $\theta_{\mathrm{c}}$ and delay angle $\theta_{\mathrm{d}}$. b) normalized output power as a function of $\theta_{\mathrm{d}}$.

Constraints (1) and (2) need to be simultaneously satisfied, so we combined them to derive the expressions of conduction angle $\theta_{\mathrm{c}}$ and normalized output power, as functions of the delay angle $\theta_{\mathrm{d}}$. The results are graphically shown in Fig. 4 for the following converter parameters: $\mathrm{U}_{\mathrm{g}}=311 \mathrm{~V}, \mathrm{f}_{\mathrm{g}}=50 \mathrm{~Hz}, \mathrm{U}_{\mathrm{dc}}=290 \mathrm{~V}, \mathrm{~L}=10 \mathrm{mH}$.

As can be seen in Fig. 4b, the maximum power is transferred to the line for $\theta_{d}=0$. Substituting $\theta_{d}=0$ into (1) and (2) we get:

$$
\mathrm{P}_{\mathrm{gN} \max }=\sin \left(\theta_{\mathrm{c} \max }\right)=\sqrt{1-\left(1-\frac{\pi}{2 \mathrm{M}}\right)^{2}} .
$$

Given the desired nominal output power, (3) imposes a constraint on dc link voltage $\mathrm{U}_{\mathrm{dc}}$ and filter inductor value $\mathrm{L}$. Therefore, attention can be put both on device voltage stress and output current harmonic content (the bigger $\mathrm{L}$, the smoother $i_{L}$ current). Equation (3) allows to calculate the conduction angle $\theta_{\text {cmax }}$, needed to transfer the required nominal power. Using (1) and (2), it is finally possible to calculate the maximum delay angle $\theta_{\text {dmax }}$, shown in Fig. 4, that corresponds to $\mathrm{P}_{\mathrm{gN}}=0$.

It is worth noting that the relation between output power and delay angle is almost linear (Fig. 4b). We verified that this "linearity" is maintained in a wide range of voltage conversion ratios $\mathrm{M}$. This property has been exploited to determine a simple modulation law for the converter which, based on a single control variable that directly controls the output power, varies the delay and conduction angles simultaneously so as to keep the fundamental component of current $i_{L}$ in phase with $u_{g}$. A similar approach is discussed in more detail, in the next section, for the DCM operation.

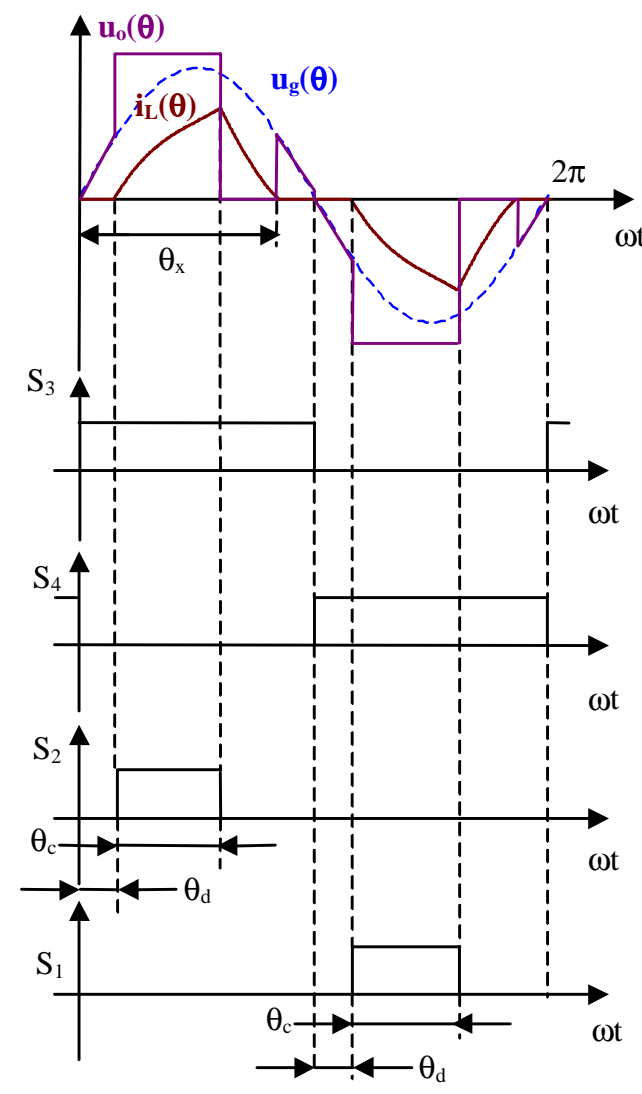

Fig. 5- Modulation strategy for DCM operation

We completed the analysis in CCM by calculating the expression of the average current $\mathrm{I}_{\text {in }}$ drawn by the inverter. Current $i_{\text {in }}$ is instantaneously equal to the inverter output current during the $\theta_{\mathrm{c}}$ interval. The output current can be calculated integrating the inductor voltage and imposing CCM operation. Averaging the instantaneous input current in a line period we get:

$$
I_{\text {in }}=\frac{U_{g}}{\pi \omega_{g} L}\left[\sin \left(\theta_{d}+\theta_{c}\right)-\sin \theta_{d}\right] .
$$

It is worth noting that the average current, drawn by the converter from the dc source, does not depend on the input voltage value $\mathrm{U}_{\mathrm{dc}}$. This implies that, in open loop conditions, the voltage set-point only depends on the dc source characteristics $\left(\mathrm{I}_{\mathrm{dc}}, \mathrm{R}_{\mathrm{dc}}\right)$, and thus can vary significantly during the operation, for example because of temperature and/or gas pressure variations within the cell. We therefore investigated also the converter's behavior in DCM.

\section{CONVERTER ANALYSIS IN DCM}

Modifying the switch control strategy as in Fig. 5, where the switch gate signals are shown, it is possible to achieve a discontinuous mode of operation. When the current in the inductor L gets to zero, it is not allowed to invert because three switches are off. With this strategy, depending on the choice of $\mathrm{L}$ and $\mathrm{U}_{\mathrm{dc}}$ the converter can operate in DCM up to the nominal power or only to a fraction of it.

As in the CCM case, we still want the current fundamental component to be in phase with the output voltage and the power extracted from the dc source to be equal to the nominal value. In this case the analysis of the 
voltage pulse fundamental harmonic component is more complicated because the waveform is no longer rectangular (Fig. 5). Therefore, the analytical expressions of the constraints we derived for the control angles are quite cumbersome and only their numerical solution is practical. The key equations are given in the Appendix. The numerical solution procedure generates Fig. 6, which shows, for different $U_{d c}$ values, the relationship between angles $\theta_{d}$ and $\theta_{c}$ that has to be satisfied to get in-phase converter current and line voltage. It is worth noting that, as in the CCM case, also in DCM the phase condition does not depend on the value of L. As can be seen in Fig. 6, differently from the CCM case, for each $U_{d c}$ value there is a minimum delay angle $\theta_{\mathrm{d}}$, below which the converter is not able to satisfy the phase condition. This limit angle increases with $\mathrm{U}_{\mathrm{dc}}$ voltage, so that Fig. 6 poses an upper limit to the $U_{d c}$ value.

Assuming that a modulation law can be implemented which varies the angles $\theta_{\mathrm{d}}$ and $\theta_{\mathrm{c}}$ according to what is shown in Fig. 6, we can easily compute the normalized power $\mathrm{P}_{\mathrm{gN}}$ transferred to the line. This is shown in Fig. 7, as a function of both angle $\theta_{c}$ and $\theta_{d}$. As can be seen, differently from the $\mathrm{CCM}$ case, the resulting relations are both non-linear. As in the CCM case, the absolute maximum power transferred to the line occurs at the minimum $\theta_{\mathrm{d}}$ angle and is inversely proportional to $\mathrm{L}$ and directly proportional to $\mathrm{U}_{\mathrm{dc}}$. A possible design procedure could consist again in selecting the DC link voltage to get a sufficiently large

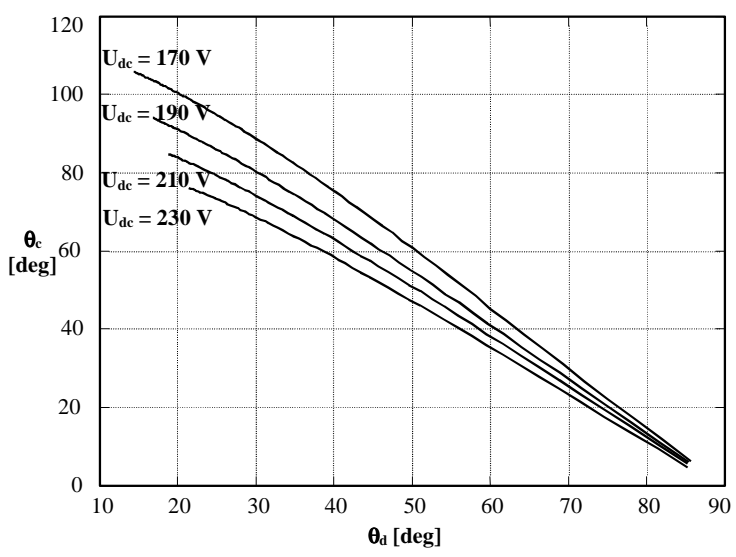

Fig. 6 - Relation between angles $\theta_{\mathrm{c}}$ and $\theta_{\mathrm{d}}$ to satisfy the phase condition for different $\mathrm{U}_{\mathrm{dc}}$ values.

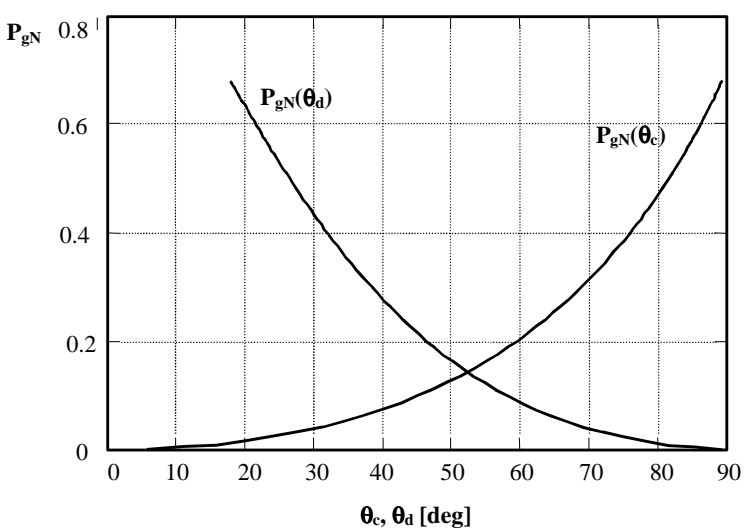

Fig. 7 - Normalized line power as a function of angles $\theta_{c}$ and $\theta_{d}$
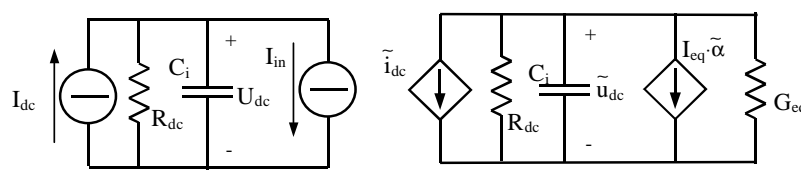

Fig. 8 - Dynamic model of the converter: large signal (left) and small signal (right)

control angle range (according to Fig. 6) and to make a proper choice of inductor $\mathrm{L}$ to get the required output power level. In order to limit line current THD, the L value should not be reduced too much. However [4] shows how this limitation can be compensated by introducing a suitable auxiliary commutation circuit.

The DCM analysis can be completed by calculating the expression of the average converter input current $I_{\text {in }}$. Following the same procedure outlined for the CCM case, we derived expression (5). As can be seen, $\mathrm{I}_{\text {in }}$ now depends on input voltage $\mathrm{U}_{\mathrm{dc}}$.

$$
\begin{gathered}
I_{\text {in }}=\frac{U_{g}}{\pi \omega_{g} L}\left[\sin \left(\theta_{d}+\theta_{c}\right)-\sin \theta_{d}-\theta_{c} \cos \theta_{d}\right]+\ldots . \\
+\frac{U_{d c}}{2 \pi \omega L} \theta_{c}^{2}
\end{gathered}
$$

In case of open loop operation, the "resistive" behavior of the power converter, implied by the last addendum of (5), helps to maintain the desired input voltage. We investigate this issue by simulations, considering different values for the $\mathrm{I}_{\mathrm{dc}}$ parameter, as a simplified model of possible operating condition variations within the cell. For a $\pm 10 \%$ variation of the $I_{d c}$ parameter, in CCM operation we found a $\pm 20 \%$ variation of the $U_{d c}$ voltage, while, in DCM, for the same output power, the $U_{d c}$ variation reduced to $\pm 6.5 \%$. This is basically the reason why we decided to design the power converter to operate in DCM up to the nominal power.

\section{CONVERTER CONTROL IN DCM}

Equation (5) can be easily linearized, by perturbation around a given operating point, with respect to variations of the $U_{\mathrm{dc}}$ voltage and of the control variable $\alpha$. Variable $\alpha$ represents the output of the controller that determines the converter operating point, i.e. angles $\theta_{\mathrm{d}}$ and $\theta_{\mathrm{c}}$. Of course, a suitable modulation law must be implemented relating $\alpha$ and the control angles $\theta_{\mathrm{d}}$ and $\theta_{\mathrm{c}}$. As explained in the following, we derived the modulation law so as to get an approximately linear relation between variable $\alpha$ and the power delivered to the line $P_{g}$, because this greatly simplifies the design of the controller.

The perturbation method allowed us to derive a small signal linear dynamic model of the power converter, which is of the type shown in the right part of Fig. 8. As can be seen, our model basically consists of two current sources: the Norton current source $I_{d c}$ with output resistance $R_{d c}$ representing the fuel cell and the current source $I_{\text {in }}$ representing the converter. The $\sim$ symbol indicates deviation of a variable around the selected operating point value. Parameters $I_{e q}$ and $G_{e q}$, shown in Fig. 8 are defined in (6). 


$$
\begin{aligned}
& \mathrm{I}_{\text {eq }}\left(\alpha, \mathrm{U}_{\mathrm{dc}}\right)=\frac{\partial \mathrm{I}_{\mathrm{in}}}{\partial \alpha}\left(\alpha, \mathrm{U}_{\mathrm{dc}}\right) \\
& \mathrm{G}_{\mathrm{eq}}=\frac{\partial \mathrm{I}_{\mathrm{in}}}{\partial \mathrm{U}_{\mathrm{dc}}}\left(\alpha, \mathrm{U}_{\mathrm{dc}}\right)=\frac{\theta_{\mathrm{c}}(\alpha)^{2}}{2 \pi \omega \mathrm{L}}
\end{aligned}
$$

The exact expression for $\mathrm{I}_{\mathrm{eq}}$ is quite complicated, as it is easy to see, because the control angles are both functions of $\alpha$, through the modulation law. However, if the linearization of the relation between $\alpha$ and the transferred power $P_{g}$ is implemented, for any given $U_{\mathrm{dc}}$ value the $\mathrm{I}_{\mathrm{eq}}$ value is constant for the entire $\alpha$ range. This happens because also the relation between $I_{\text {in }}$ and $\alpha$ in this case becomes linear. Therefore, linearizing the relation between $\alpha$ and $\mathrm{P}_{\mathrm{g}}$ eliminates the problem of a variable small signal gain when it comes to controlling the power converter, giving a significant advantage in the controller design.

To derive the modulation law, satisfying the phase condition and being simple enough to be easily implemented, a suitable linear approximation of the relations shown in Fig. 6 can be determined. Then, angles $\theta_{\mathrm{d}}$ and $\theta_{\mathrm{c}}$ can be generated as a function of a single variable, which we call $\gamma$. A non linear function $f$ which approximates the inverse of the resulting relation between $\mathrm{P}_{\mathrm{g}}$ and $\gamma$ can then be determined and used to process the control variable, before angles $\theta_{\mathrm{d}}$ and $\theta_{\mathrm{c}}$ are computed. We found that a quadratic approximation is normally good enough to achieve the desired linearization. Of course, this solution is viable only in case of a digital implementation of the control system, as in our case. We consequently developed the modulator based on the following equations:

$$
\begin{aligned}
& \gamma=\mathrm{f}(\alpha) \\
& \theta_{\mathrm{c}}=\mathrm{m}_{\mathrm{c}} \cdot \gamma+\theta_{\mathrm{c} 0}, \\
& \theta_{\mathrm{d}}=\mathrm{m}_{\mathrm{d}} \cdot \gamma+\theta_{\mathrm{d} 0}
\end{aligned}
$$

where $\alpha$ is the actual control variable $(0<\alpha<1)$ which now linearly controls the normalized power transferred to the line, $f$ is the non linear function that linearizes the relation between $\alpha$ and the transferred power, $\mathrm{m}_{\mathrm{c}}, \theta_{\mathrm{c} 0}, \mathrm{~m}_{\mathrm{d}}, \theta_{\mathrm{d} 0}$ are control parameters, to be determined by approximating the relation between $\theta_{\mathrm{d}}$ and $\theta_{\mathrm{c}}$, depicted in Fig. 6 , and corresponding to the selected input voltage. Another constraint can be imposed for the control angle $\theta_{\mathrm{c}}$. This can be limited between $10^{\circ}$ and $90^{\circ}$ because below $10^{\circ}$ there is practically no power variation, while the maximum power is reached when $\theta_{\mathrm{c}}=90^{\circ}$ (Fig. 7).

\section{CONTROL DESIGN EXAMPLE}

In our example we assume $U_{g}=160 \mathrm{~V}$. Based on Fig. 6 and on reasonable switch ratings we chose $U_{d c}=200 \mathrm{~V}$. By selecting $\mathrm{L}=10 \mathrm{mH}$ we got a maximum output power $\mathrm{P}_{\text {gMAX }}=2230 \mathrm{~W}$ and, according to the previously outlined procedure, we determined the following parameter values: $\mathrm{m}_{\mathrm{c}}=1.396, \mathrm{~m}_{\mathrm{d}}=-1.117, \theta_{\mathrm{c} 0}=0.175, \theta_{\mathrm{d} 0}=1.46$. With these values, the resulting relation between $\gamma$ and the line power $\mathrm{P}_{\mathrm{g}}$ is shown in Fig. 9. After function $f$ was determined approximating the inverse of the relation $\mathrm{P}_{\mathrm{g}}(\gamma)$, we obtained the relation between the control variable $\alpha$ and $\mathrm{P}_{\mathrm{g}}$, also shown in Fig. 9. As can be seen, a good linearity is achieved.

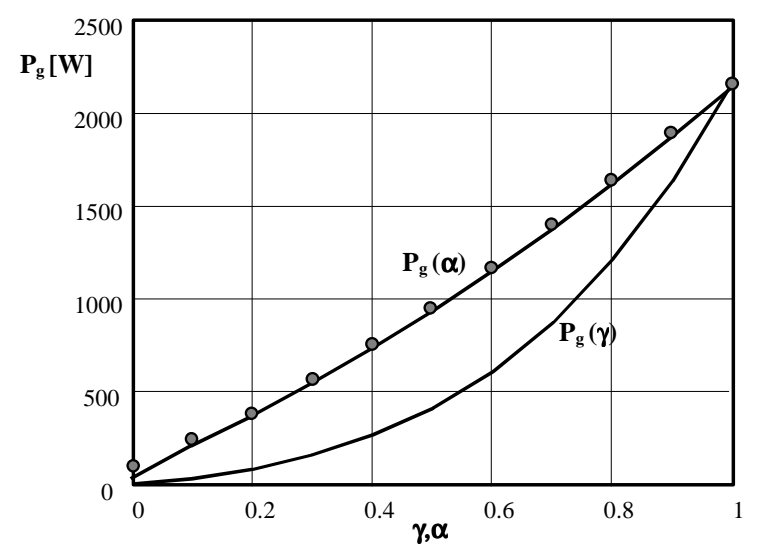

Fig. 9 - Line power as a function of control variables $\gamma$ and $\alpha$, computed for $\mathrm{U}_{\mathrm{g}}=160 \mathrm{~V}, \mathrm{U}_{\mathrm{dc}}=200 \mathrm{~V}, \mathrm{~L}=10 \mathrm{mH}$. Dots represent simulation results.

Based on the linear model in Fig. 8, a controller can be found that allows to regulate the input voltage $U_{d c}$ and to extract the desired active power from the source. Given the first order structure of the system, a suitable choice can be a PI regulator, which is possible to design locating the regulator's zero at the system's pole frequency and then fixing the integral gain $\mathrm{k}_{\mathrm{I}}$ so as to get the desired crossover frequency $\omega_{\mathrm{cr}}$, according to (8).

$$
\begin{aligned}
& \frac{\mathrm{k}_{\mathrm{P}}}{\mathrm{k}_{\mathrm{I}}}=\frac{\mathrm{C}}{\mathrm{G}_{\mathrm{eq}}+1 / \mathrm{R}_{\mathrm{dc}}} \\
& \mathrm{k}_{\mathrm{I}}=\frac{\left(\mathrm{G}_{\mathrm{eq}}+1 / \mathrm{R}_{\mathrm{dc}}\right) \cdot \omega_{\mathrm{cr}}}{\mathrm{I}_{\mathrm{eq}}}
\end{aligned}
$$

In order to verify the results of this analysis, Pspice simulation of the system was performed. Initially we verified the correctness of the modulation law by evaluating, for different $\alpha$ values, the resulting transferred power and comparing it with the analytical result of Fig. 9. The results are shown as dots in Fig. 9.

We successively verified the open loop and closed loop performance of the system. In open loop conditions we verified that our model is capable of predicting with good accuracy both voltage variation and settling time in response to a step variation of $I_{d c}$. In closed loop conditions we checked the performance of the PI controller we designed according to the given procedure. A typical response to step variations of the $\mathrm{I}_{\mathrm{dc}}$ current is shown in Fig. 10.

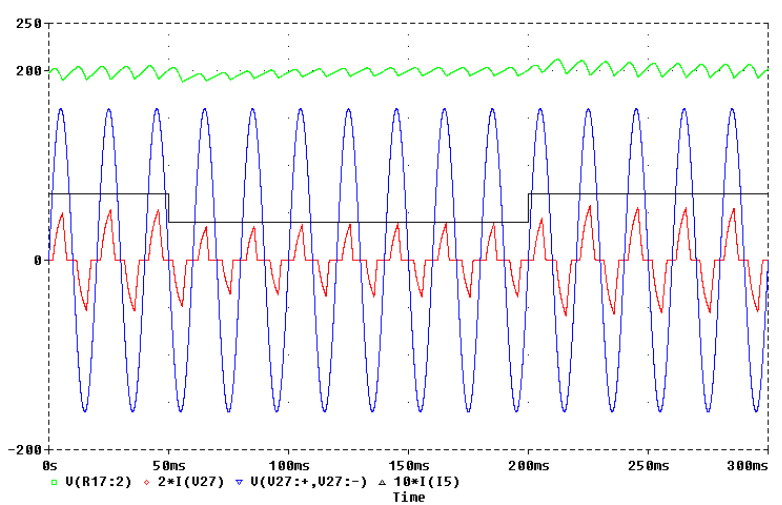

Fig. 10 - Simulated converter operation with PI control. From top to bottom: regulated $\mathrm{U}_{\mathrm{dc}}$ voltage, line voltage, input current (X10) and line current $(\mathrm{X} 2)$ 


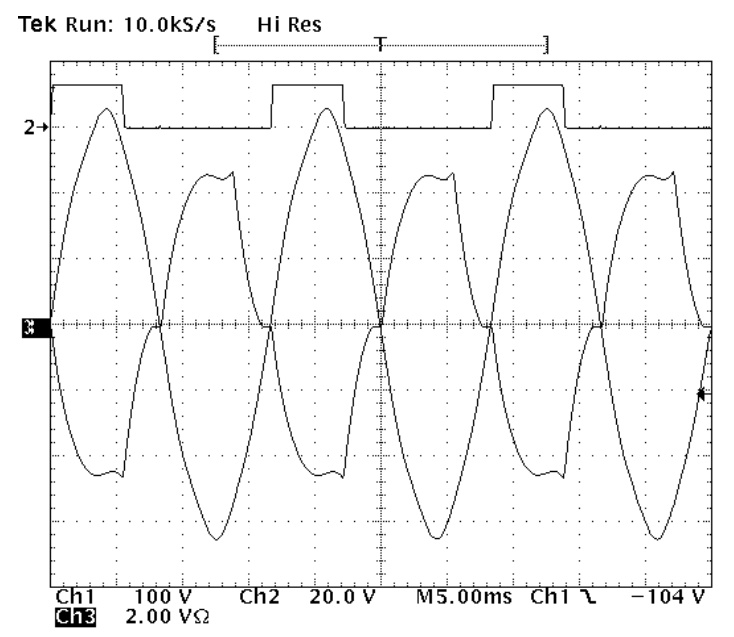

Fig. 11- Converter operation at reduced power. From top to bottom: $\mathrm{S}_{2}$ command, input voltage [100V/div], line current [2A/div].

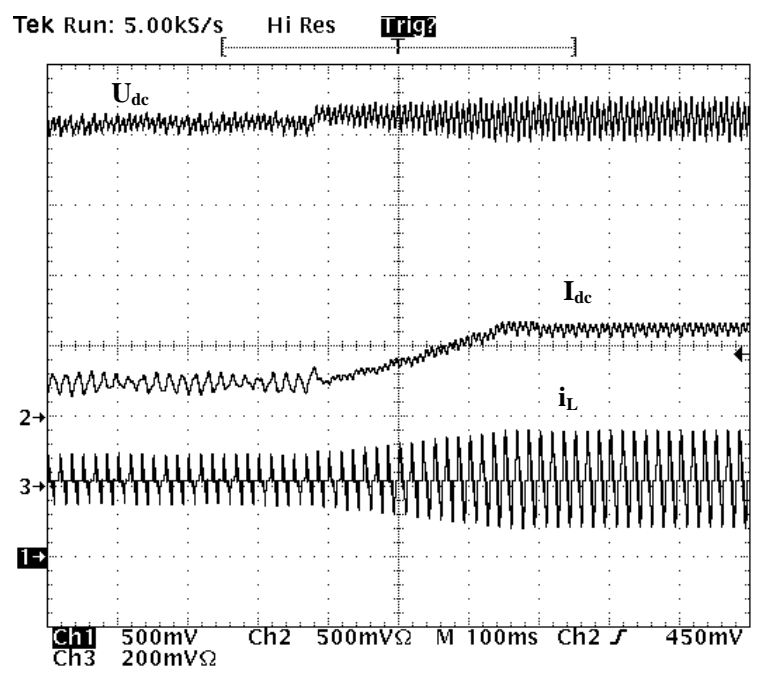

Fig. 12 - Dynamic behavior of the controller. From to to bottom: voltage $U_{d c}(10 \mathrm{~V} /$ div $)$, current $I_{d c}(2 \mathrm{~A} /$ div $)$, line current $i_{L}$ (5A/div).

\section{EXPERIMENTAL RESULTS}

A first prototype of the converter, designed for a reduced output power of $800 \mathrm{~W}$, is currently under test. The dc supply is a laboratory power supply. We show in Fig. 11 an example of operation in DCM. The line voltage is $220 \mathrm{~V}_{\mathrm{RMS}}$, the circuit injects $740 \mathrm{~W}$ into the grid. The PF is 0.985 . Fig. 12 shows instead the dynamic performance of the control system. A linear variation of $I_{d c}$ current (middle trace) determines a $U_{d c}$ voltage rise (top trace) which is compensated by the control system by increasing the injected line current (bottom trace).

\section{CONCLUSIONS}

This paper analyses a single phase, low frequency commutated VSI usable as a rugged and low-cost interface between a renewable dc source and the utility grid. The target application is represented by low to medium power fuel cells used in co-generation systems. Switching at the line frequency, the converter presents negligible switching losses and EMI generation. Moreover, the simplicity of the required control circuitry makes it particularly robust and inexpensive. The paper includes the detailed analysis of the converter in CCM and DCM. The analysis allows to outline a design procedure both for the converter passive components and for the basic control parameters, defining an optimal modulation strategy. Experimental results are also given, that validate the theoretical analysis and demonstrate the feasibility of the approach.

\section{REFERENCES}

[1] - G. A. O’Sullivan, "Fuel Cell Inverter for Utility Applications", CDROM of the IEEE Power Electronics Specialists Conference, Galway, Ireland, June 2000

[2] - U.S. Department of Energy et al., "2001 Future Energy Challenge", Homepage URL: HYPERLINK http://energy.uiuc.edu/energychallenge/main.html/FutureEnergyCha llenge

[3] - G. Ledwich and P. Wang, "Simple Grid Interfaces for Renewables", International Journal of Renewable Energy Engineering, vol. 1, No. 2, August 1999, pp. 50-55.

[4] - G. M. Martins, J. A. Pomilio, S. Buso, "A Single-Phase Lowfrequency Commutation Inverter for Renewables", IECON'01 Conf. Proc., Denver, USA, November 2001, pp. 1976-1981.

[5] - M.A. Brown, T.L. Pryor, P. Singh, "Comparison of Diesel Generator, Proton Exchange Membrane Fuel Cell and Alkaline Fuel Cell System Efficiencies for the Production of AC Power in Remote Area Power Supply Applications", International Journal of Renewable Energy Engineering, Vol. 3, No. 2, August 2001, pp.297-304.

[6] - K. Kordesch, G. Simader, Fuel Cell and Their Applications, VCH Verlagsgesellschaft mbH, 1996.

[7] - E. Santi, D. Franzoni, A. Monti, D. Patterson, F. Ponci, N. Barry, "A Fuel Cell Based Domestic Uninterruptible Power Supply", APEC 2002 Conf. Proc., Dallas, USA, March 2002, pp. 605-613.

\section{APPENDIX}

In DCM the condition determining in phase line current and voltage is given by:

$\left[\cos \left(\theta_{\mathrm{d}}\right)-\cos \left(\theta_{\mathrm{d}}+\theta_{\mathrm{c}}\right)\right]+\mathrm{k} \cdot \pi+\mathrm{k} \cdot\left(\theta_{\mathrm{d}}-\theta_{\mathrm{x}}\right)+\ldots$

$\ldots+\frac{\mathrm{k}}{2} \cdot\left[\sin \left(2 \theta_{\mathrm{x}}\right)-\sin \left(2 \theta_{\mathrm{d}}\right)\right]=\mathrm{k} \cdot \pi$

where (see also Fig. 5)

$\theta_{\mathrm{x}}=\mathrm{a} \cos \left(\cos \left(\theta_{\mathrm{d}}\right)-\frac{\mathrm{U}_{\mathrm{dc}}}{\mathrm{U}_{\mathrm{g}}} \cdot \theta_{\mathrm{c}}\right)$

and $\mathrm{k}=\frac{\mathrm{U}_{\mathrm{g}}}{2 \cdot \mathrm{U}_{\mathrm{dc}}}=\frac{1}{2 \cdot \mathrm{M}}$. It is worth noting that (A1) is a generalization of

(1), where the second addendum is determined by the different voltage pulse waveform typical of DCM, which presents also sinusoidal components i.e. it is no longer a three level voltage pulse. Equation (A1) can be simplified and re-written as follows:

$\frac{1}{\mathrm{k}} \cdot\left[\cos \left(\theta_{\mathrm{d}}\right)-\cos \left(\theta_{\mathrm{d}}+\theta_{\mathrm{c}}\right)\right]+\theta_{\mathrm{d}}-\theta_{\mathrm{x}}+\ldots$

$\ldots+\frac{1}{2} \cdot\left[\sin \left(2 \theta_{\mathrm{x}}\right)-\sin \left(2 \theta_{\mathrm{d}}\right)\right]=0$

The power transferred to the line is instead given by:

$\mathrm{P}_{\mathrm{gN}}=\left[\sin \left(\theta_{\mathrm{d}}+\theta_{\mathrm{c}}\right)-\sin \left(\theta_{\mathrm{d}}\right)\right]+\ldots$

$$
\ldots+\left[-\frac{\mathrm{k}}{2} \cdot\left(\cos \left(2 \theta_{\mathrm{d}}\right)-\cos \left(2 \theta_{\mathrm{x}}\right)\right)\right] \text {, }
$$

which can be interpreted again as a generalization of (2), where the second addendum is due to the sinusoidal components of the inverter voltage pulse. 